MATEC Web of Conferences 22,04028 (2015)

DOI: $10.1051 /$ matecconf/ 20152204028

(C) Owned by the authors, published by EDP Sciences, 2015

\title{
External Prestressing Bridge Reinforcement Technology Review
}

\author{
Hanbing Zhu \& Yaxun Yang \\ Key Laboratory for Old Bridge Detection and Reinforcement Technology of Ministry of Transportation, \\ Chang'an University, Xi'an, Shaanxi, China
}

Weiya Fan

Chang'an University, Xi'an, Shaanxi, China

\begin{abstract}
Externally prestressed bridge can not only limit and reduce the cracks and deformation of the structure, improve the rigidity and bearing capacity of structure, improve the stress state of structure, but also have less interference for bridge operation when it is operating and have the good economic efficiency. This paper introduces the advantages and disadvantages of external prestressed strengthening technique, its calculation theory and construction technology described in detail, and finally the paper discusses the deficiency of existing research.
\end{abstract}

Keywords: Externally prestressed; Old bridge reinforcement; theory of computation; construction process

\section{INTRODUCTION}

Bridge is an important part of road to ensure smooth highway, and its carrying capacity and the use of performance is the key of all the line. As the growth of the bridge use time, inevitably there will be function attenuation, situation of structure aging and structure damage. And the use of performance will degrade because of the improper design and poor quality of the construction. If the situation that it doesn't obtain the timely and effective maintenance happens, its performance will be greatly affected. When structural damage appears, there will pose a great threat to people's lives. So, we must analyze the cause of bridge damage carefully, adopt the corresponding maintenance with plane, and use less capital investment to prolong the service life of the bridge and meet the needs of traffic flow ${ }^{[1]}$. All of these are urgent tasks that are meaningful and have far-reaching influence in the development of highway construction in our country.

\section{ADVANTAGES AND DISADVANTAGES OF EXTERNAL PRESTRESSING SYSTEM ${ }^{[2]}$}

\subsection{Advantages of external prestressing system}

1) With externally prestressed tendon changes direction by steering blocks, it is the broken line layout, with which reinforcements only contact with concrete at the steering block, and it can greatly reduce the prestressed friction loss and improve the effect of prestressing effect.

2) Reinforcement layout is outside the web, which can avoids the phenomenon that concrete is not vibrated compactly, which is caused by the close corrugated pipe in the web. As for the box girder structure, because the thickness of box girder' rids are most decided by construction needs such as pouring concrete, using externally prestressed tendon can further reduce the thickness of the web and the weight of dead load.

3) The external tendons are in the polyethylene pipe or tube, so it's easy to set up, inspect and replace the external tendon during the period of use, and it's convenient and more reliable for grouting.

4) Reinforcement layout is outside the section of structure, and there is no bond between reinforcement and concrete, change of stress caused by load disperses on the full length of the prestressed tendon. Because of these, the variation of stress is small, and it's quite good for the bridge that bears larger live load and is controlled by the fatigue.

5) External prestressing technique can shorten the construction period of large-span precast prefabricated bridges.

\subsection{Defects of external prestressing system $^{[3]}$}

1) External tendon is easy to be on fire, damaged and it bears vibration, therefore, we should limit the free length of external tendon.

2) Anchorage zone and steering blocks bear huge local concentrated force, so the structure is very heavy.

3) The actual eccentric of external tendon is small, and its flexural capacity is less than the bonded prestressed concrete structure under the limit state.

4) Externally prestressed structure may be failure without warning due to the lack of ductility under the limit state.

\section{DESIGN AND CALCULATION METHOD OF EXTERNALLY PRESTRESSED TENDONS ${ }^{[4]}$}

Double mansard is the simplest and most effective form for external tendon, as shown in Figure 1 a). 
3.1 Calculation of internal force increment of external tendon

It's a statically indeterminate structure within the whole system. As for external system, it's a statically determinate structure, and the structure is in the balance with the joint action of dead load and prestressed load. After the reinforcement, the stress calculation of concrete beam section should calculate internal force increment under live load. Under the influence of live load, the internal force ratio of oblique reinforcement $\left(\mathrm{N}_{\mathrm{b}}\right)$ and horizontal reinforcement $(\mathrm{N})$ is $\mathrm{k}$ :

$N_{b}=k N=\frac{1}{\cos a \pm f_{0}} N$

Where, $f_{0}$ is the friction factor between reinforcement and steering block, and it's negative when being pulled outward; $a$ is the Angle between oblique reinforcement and horizontal reinforcement.

Take the internal force of middle span's horizontal reinforcement as redundant forces. When $\mathrm{N}=1$, bending moment diagram (Figure 1b), axial force diagram (Figure 1c) and bending moment diagram under live load (Mp, Figure 1d) are shown in Figure 1. The equations of mechanics are shown as follow:

$\delta_{11} \Delta N+\Delta_{1 P}=0$

$\delta_{11}=\sum \int \frac{\bar{N}^{2} d s}{E A}+\sum \int \frac{\bar{M}^{2} d s}{E I}$

$=\frac{l-2 l_{1}}{E_{\mathrm{y}} A_{\mathrm{y}}}+\frac{2 k^{2}\left(l_{1}-l_{2}\right)}{E_{\mathrm{y}} A_{\mathrm{y}} \cos \alpha}+\frac{2 k^{2} \cos ^{2} \alpha\left(l_{1}-l_{2}\right)+l-2 l_{1}}{E A_{0}}$

$+\frac{e_{2}^{2}}{E I}\left(l-2 l_{1}\right)+\frac{2 k^{2}\left(l_{1}-l_{2}\right)}{E I}\left[\mathrm{e}_{1}^{2} \cos ^{2} \alpha\right.$

$\left.-e_{1} \cos \alpha \sin \alpha\left(l_{1}-l_{2}\right)+\frac{1}{3} \sin ^{2} \alpha\left(l_{1}-l_{2}\right)^{2}\right]$

$\Delta_{1 p}=-\frac{2}{E I} \int_{1}^{\frac{1}{2}} M_{\mathrm{p}} e_{2} d x$

$+\frac{2}{E I} \int_{1}^{l_{1}} M_{p}\left[e_{1} k \cos \alpha-k \sin \alpha\left(x-l_{2}\right)\right] d x$

Internal force increment and stress increment are shown as follow.

$\Delta N=-\Delta_{1 \mathrm{p}} / \delta_{11}$

$\Delta \sigma_{y}=-\Delta N / A_{\mathrm{y}}$

The stress of external tendon under using load should satisfy the following conditions.

$\Delta \sigma_{y}=\Delta \sigma_{y e}+\Delta \sigma_{y} \leq 0.6 R_{\mathrm{y}}^{j}$

Where, $\sigma_{y e}, E$ are effective prestress and the elastic modulus of prestressed reinforcement; I,E are beam section's moments of inertia, elastic modulus of concrete; $A, A_{y}, A_{0}$ are the area of section, the area of externally prestressed tendons, and the area of conversion section; $R_{y}^{j}$ is the ultimate strength of externally prestressed tendons.

The rest meaning of symbols are shown in Figure 1.

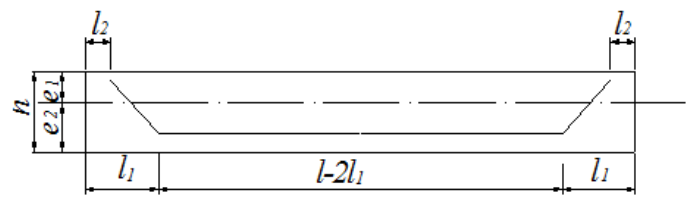

a) structure

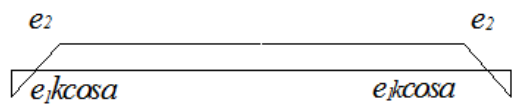

b) bengding moment

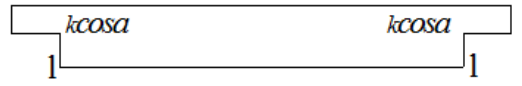

c) axial force

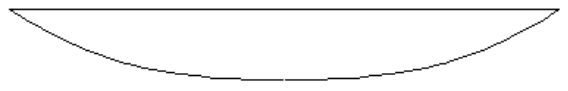

d) $\mathrm{Mp}$

Figure 1. Reinforcing system computational scheme

\subsection{Reinforcement design of external cable}

3.2.1 Determine the area of external cable

Area of externally prestressed tendons is determined by bending strength of mid-span Section. Its specific steps are shown in Figure 2.

\subsubsection{Stress loss of externally prestressed tendons and the tension control stress}

The calculation method of stress loss of prestressed concrete beams is basically the same with ordinary when using external prestressed strengthening old bridge. Due to the long time use of the old bridge , the stress loss caused by concrete shrinkage and creep damage is calculated according to "highway bridge design specification", and the result is $20 \% \sim 30 \%$ reduction. Tension control stress of prestressed cable can generally be reduced about $10 \%$ in order to avoid the situation that prestressed cable is at a high stress state for a long time. 


\subsection{Crack calculation of reinforcing system}

Place the mechanical characteristics of concrete beam strengthened by externally prestressed tendons belong to the partial prestressed concrete structure, but it tends to be the nature of the reinforced concrete beam, because there is no bond between reinforcement and concrete. And the calculation of reinforcement stress $\left(\delta_{g}\right)$ of partial prestressed concrete beam starts from the state of pressure dissipation, so after reinforcement, the calculation of crack width is still using the current formula inside the bridge gauge.

Check bearing capacity of old bridge and calculate the bearing capacity after reinforcement.

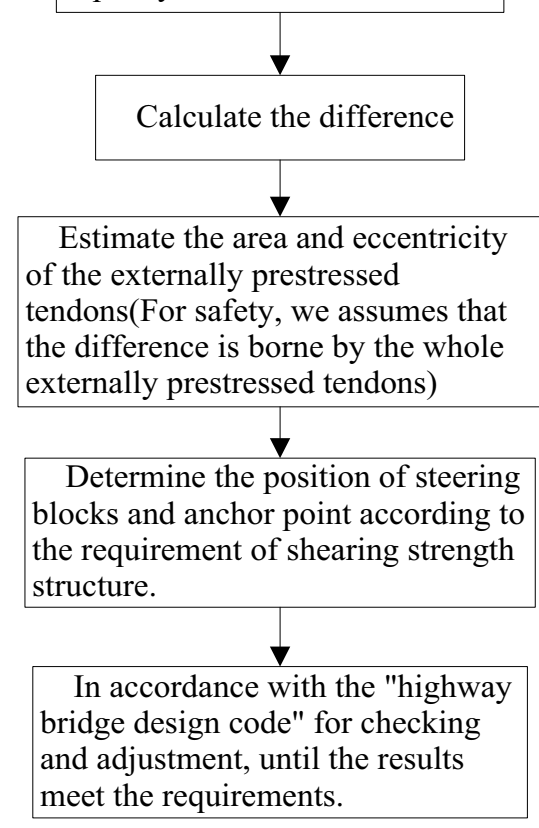

Figure 2. The flow chart of determining the area of external cable

$\delta_{f \max }=C_{1} C_{2} C_{3} \frac{\sigma_{g}}{E_{g}}\left(\frac{30+d_{0}}{0.28+10 \mu}\right) \leq\left[\delta_{f}\right]$

Where, $C_{I}$ is the parameters of considering component force characteristic, and for flexural member, $C_{l}=$ 1.0; $C_{2}$ is the parameters of considering steel surface shape, and for crude steel, $C_{2}=1.0 ; C_{3}$ is the parameters of considering load, and for a long time or repeat , $C_{3}=1.5$.

The parameters are calculated by the use of the highway bridge gauge. But in the calculation of reinforcement ratio $(\mu)$, we only consider the area of reinforcement $\left(A_{g}\right)$ in original beam. Equivalent diameter $\left(d_{0}\right)$ is also only determined by the diameter of reinforcement in original beam.

Considering that reinforced beam is reinforced concrete structure, most of the beams use reinforcement. Because of this, the available crack width $\left(\delta_{f}\right)$ is determined still according to the reinforced concrete structures.

\section{CONSTRUCTION TECHNOLOGY OF EX- TERNAL PRESTRESSING REINFORCEMENT}

\subsection{Construction process}

Drilling, bonding carbon fiber and the tension prestress are the key steps of external prestressing reinforcement technology in the process of construction [5].

As for T type bridge, drilling in the web is the most difficult and important step. When drilling in the web, we cannot touch the reinforcement of the bridge, and we must bond carbon fiber $\left(30 \mathrm{~cm}^{*} 30 \mathrm{~cm}\right)$ in the mouth of the cave in order to strengthen local compressive ability of bridge concrete. After drilling in the web, it's time to begin tension prestress. After completion of the tension prestress, it's time for the installation of anchor cup and clip nut. After that, calculate the actual elongation of wire rope according to the piston elongation of the Jack. In the general case, estimate the actual elongation and the actual error, and compare with the theoretic elongation, so the error must be controlled between 5\%-10\%. Only in this way, can we guarantee the reinforcement effect for a long time.

The process of pulling reinforcement is shown in Figure 3.

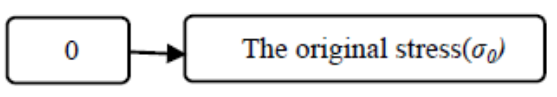

\section{Record the elongation}
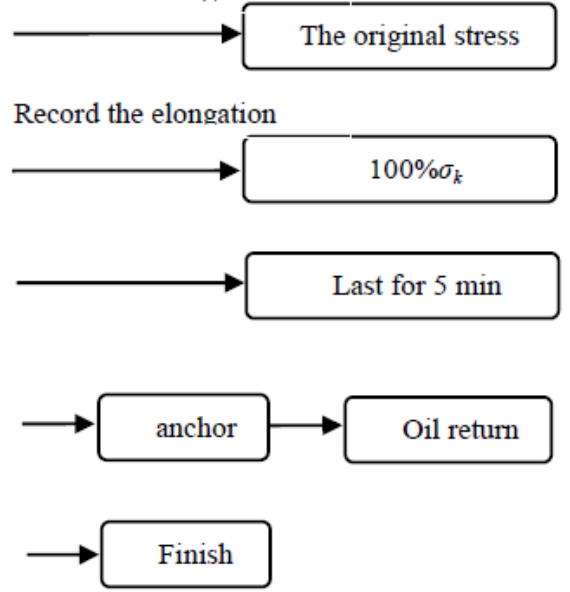

Figure 3.The flow chart of pulling reinforcement 


\subsection{Prestressed cable arrangement}

Generally speaking, the reinforcement system of external prestress mainly has five forms. The forms are shown in Figure 4. Among these five kinds of forms, they can be divided into three categories according to the reinforcement which is as a whole or not ${ }^{[6]}$.

The first category is made up of horizontal reinforcing steel bar and bent up bar, and is linked together through the slider to control the size of the tension. Or it controls the size of the tension through bend steel bending, and it is shown in Figure 4 (a). Or the reinforcement can be in the bottom of beam, which is shown in Figure 4 (b).

The second type is that horizontal reinforcing steel bar and bent up bar are composed of complete steel, and the reinforcement can be in the bottom of the beam, which is shown in Figure 4 (c), and it can also be in the top of the beam, which is shown in Figure 4 (d).

The last category consists of ordinary metal products and steel. Bending part is made of steel tank, it should be fixed on the wedge slide block of end beam while using, and the horizontal reinforcement is made of steel ridge or high strength of the tow, which is shown in Figure 4 (e)

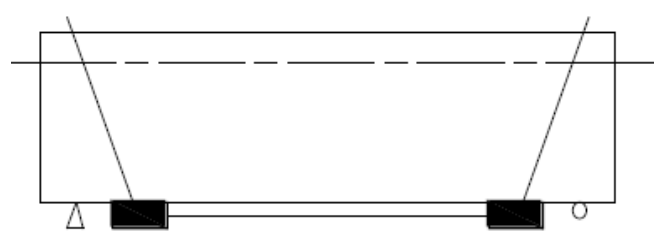

(a)

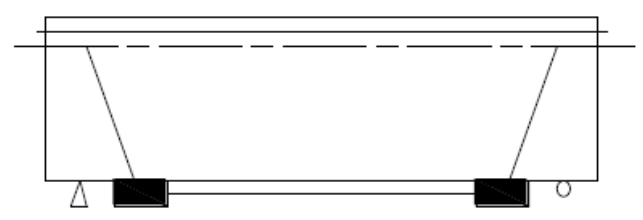

(b)

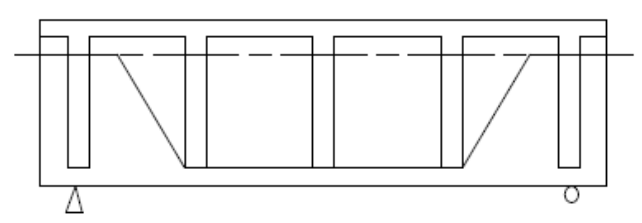

(c)

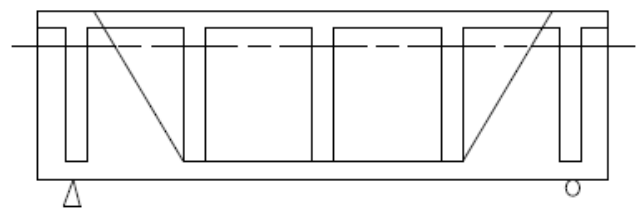

(d)

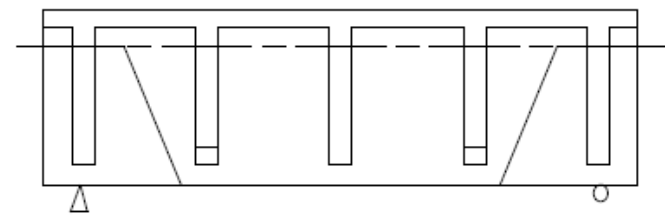

(e)

Figure 4. Prestressed cable arrangement

\subsection{Attention matters of reinforcement tension}

1) When strength of block and elastic modulus of concrete anchor block have reached $100 \%$, we can pull reinforcement.

2) Forbid all traffic on the bridge while pulling reinforcement.

3) After finish pulling reinforcement, prestressed tendon should leave sufficient anchorage length in order to pull reinforcement again when the prestressed tendon becomes loose.

4) Tools like Jack and oil pump should be used by professional person, and should be taken regular maintenance.

5) Vibration control devices should be installed in beam in order to avoid vibration caused by the situation that prestressed tendon length is too long.

5 LACK OF EXTERNAL PRESTRESSING REINFORCEMENT TECHNOLOGY RESEARCH

\subsection{Existing research scope}

1) The damage forms externally prestressed reinforcement beam.

2) The bearing capacity calculation of externally prestressed reinforcement beam mainly concentrates in the calculation of normal section, and the calculation of inclined section is rare.

3) The stress calculation of externally prestressed tendon includes the loss of prestress ${ }^{[7]}$, the calculation of stress increment, the influence of second-order effect on the bearing capacity of the reinforced bridge and the slip of externally prestressed tendons in the location of steering blocks, and so on.

4) The research of steering device, anchor device and other local structure is carried out.

5) Research on dynamic behavior of externally prestressed reinforcement structures is carried out. 


\subsection{Deficiency of research}

Although many experimental study of the external prestressing system have been done at home and abroad, the mechanism and design theory of prestressed reinforcement technology is still immature. Especially a large number of bridges built in the last century whose span are medium and small lack the widely appropriate reinforcement standard. The details and force analysis of anchorage of externally prestressed tendons and the structure of the steering device are not clear in the current standards and specifications in our country ${ }^{[8]}$, and the relevant experimental study is also rare. So, it needs a large number of studies in order to widely use the external prestressing reinforcement technology in bridge reinforcement project in our country.

\section{CONCLUSION}

Externally prestressed reinforcement technology can well meet the requirements of using load, improve the ultimate bearing capacity ${ }^{[9]}$, improve the use performance of the old bridge, reduce the reinforcement stress amplitude and control crack, increase the lifespan and durability of the structure ${ }^{[10]}$. The effect of this strengthening method is good and it's easy to control construction quality. It is a kind of ideal reinforcement method and it has a broad development prospects.

\section{ACKNOWLEDGEMENTS}

I would like to express my gratitude to all those who helped me during the writing of this thesis. I gratefully acknowledge the help of my supervisor, Mr. Yaxun Yang, who has offered me valuable suggestions in the academic studies. In the preparation of the thesis, he has spent much time reading through each draft and provided me with inspiring advice. Without his patient instruction, insightful criticism and expert guidance, the completion of this thesis would not have been possible.

I also owe a special debt of gratitude to all the professors in Chang'an University, from whose devoted teaching and enlightening lectures I have benefited a lot and academically prepared for the thesis.

I should finally like to express my gratitude to my beloved parents who have always been helping me out of difficulties and supporting without a word of complaint.

\section{REFERENCES}

[1] Qian Liao. \& Ning Tan. 2014. External Prestressing Application In Bridge Reinforcement. Sichuan Construction, 34(6)
[2] Hailiang Wan, yong Den. 1997. The development Status and Discussion of Externally Prestressed Concrete Bridge. Journal of Shijiazhuang railway Institute, 10(2).

[3] Dianwen Zhu, Xiaobing Tang. \& Pingwan Zhang. 2002. Bridge Structure of External Prestressing Reinforcement Technology. Transportation Science and Technology, (6).

[4] Wenliang Lu. \& Wenhui Li. 2000. The Calculation Method of Externally Prestressed Reinforcement In Reinforced Concrete Simply Supported Beam of Railway. Railway Standard Design, 20(2).

[5] Haidong Wang. 2013. Highway bridge construction of technology the externally prestressed reinforcement. Science and technology of Heilongjiang traffic, (10).

[6] Quanjie, Biao Wan. 2014. External Prestressed Strengthening Technique Research In Highway Bridge Construction. Science and Technology of Heilongjiang Traffic, (10).

[7] Jianfeng Li. 2006. The Bridge Engineering Aapplication of External Prestressing Reinforcement Technology. Fujian Architecture, (2).

[8] Zhiqiang Xu. 2007. The Research and Development of External Prestressing Technology. Roads and Trucks, (123).

[9] Jie Gu. 2009. External Prestressing Bridge Reinforcement Technology. Science and Technology of Heilongjiang Traffic, (4).

[10]Rongsheng Li. 2012. Design and Construction of Externally Prestressed Reinforcement. Science and Technology of Heilongjiang Traffic, (10).

[11]Dazhong Chen. 2010. Externally prestressed reinforcement construction technology of Highway bridge. Chinese new technology and new products, (3) : 113-114.

[12]Jianfan Liu. 2013. Reinforcement construction technology and quality control of Highway Bridges. Wizard of science and technology to become rich, (2) : 231, 235.

[13] Shuixing Zhou, Zhaoyi He. \& Yisong Zhou. 2001. Construction calculation manual of road and bridge. People's traffic press.

[14] Technical specification for construction of highway bridge( JTJ041-2000) [S]. People's traffic press, 2007.

[15] Meisong Zheng. \& Xiaoyong Xu. 2010. The application of external prestressing reinforcement technology in highway bridge construction. Sichuan building materials, $8(14): 56-58$

[16]Liming Jiang. 2011. Principle and method of external prestressed strengthening bridge[j]. Traffic world, 6(37) : 98-100.

[17]Xiuwen Zhao. \& Lei Zeng. 2004. The bridge reinforcement technology of highway construction. Roads and Trucks, (2).

[18] Jie Yang. 2013. The bridge reinforcement technology. Traffic word, 12.

[19]Zhiyu Wang. 2015. Present situation of bridges development and the reinforcement method research in our country. Shandong industrial technology, 01.

[20]Guiping Yang. 2006. Discussion of carbon fiber reinforced bridge technology. Roads and Trucks, (4).

[21]Bin Niu. 2003. Limit state analysis of externally prestressed concrete. Journal of civil engineering, 33(3). 